\title{
Evidence-Based Dentistry in a Developing Economy - the Nigerian Example
}

\author{
Akadiri Oladimeji Adeniyi*,1 and Adeyemo Wasiu Lanre ${ }^{2}$ \\ ${ }^{I}$ Department of Oral and Maxillofacial Surgery, College of Health Sciences, University of Port Hacourt, Rivers, \\ Nigeria \\ ${ }^{2}$ Department of Oral and Maxillofacial Surgery, College of Medicine, University of Lagos, Nigeria
}

\begin{abstract}
:
Background

Evidence-based dentistry (EBD) is becoming popular all over the world with the increasing global involvement of dental practitioners in the debates on the relevance or otherwise of EBD. However, very little has been known on the evolutionary trend of EBD in the developing countries of the world.
\end{abstract}

\begin{abstract}
Aims and Objectives
This pilot study was designed to assess the state of EBD in the accredited dental schools in Nigeria as an example of a developing economy.

\section{Methodology}

An electronic search was conducted for articles on the subject of EBD emanating into the world dental literature from Nigeria as a measure of activities in the field of EBD in the country. Further investigation was done by way of interviews of faculty members and resident doctors in the four fully accredited dental schools in Nigeria. The subject of the interview was premised around the evaluation of activities in the field of EBD.

\section{Results}

Only 6 relevant articles were found in the search. The interviews however revealed an increasing awareness but low level of knowledge of the principles of EBD in the dental schools. Major obstacles were infrastructural limitations and lack of personal motivations. The enthusiasm of the younger faculties and resident doctors was notable.

\section{Conclusion}

It was obvious that EBD is yet to assume the desired momentum in the $21^{\text {st }}$ century in Nigeria. It is however gladdening that there is a promising future for EBD with the rising enthusiasm noted among the younger generation of clinicians.
\end{abstract}

Keywords: Evidence-based dentistry, Evidence-based dental practice, 21st century, Nigeria.

\section{INTRODUCTION}

The field of Evidence- based Health care (EBH) is rapidly evolving worldwide. It is a change instrument that preaches a departure from the traditional approach to medical practice where decisions were based solely on individual's training and experience to one driven by the best available evidence in the world literature. Like every other change element, it is not surprising that Evidence-based health care has been massively criticized and scrutinized over the past decades [1,2].

The philosophy of Evidence-based health care is not new; it dates back to mid- $19^{\text {th }}$ century when Dr Pierre Louis and Dr Maurizio Buffalini introduced the concept in Paris

*Address correspondence to this author at the P.O. Box 212, Choba, Port Harcourt, Rivers State, Nigeria; Tel: (+234)-808-709-9694;

E-mail: oaakadiri@yahoo.com and Florence respectively [3]. However, the birth of modern evidence-based practice (EBPr) can be traced to a publication by the Department of Clinical Epidemiology and Biostatistics of McMaster University, Canada, barely over a decade ago [3]. Since then, the discipline has become a hot subject and a number of journals dedicated to the subject have evolved.

Despite the rapid development lately, many practitioners are still reluctant to adopt evidence-based principles in their day-to-day practice; citing a number of obstacles and limitations. Thankfully, the recent growth spurt in Information and Communication Technology (ICT) during the $21^{\text {st }}$ century has eased off most of the constraints against the practice of Evidence-based health care in the developed world. But, can this be said of the underdeveloped countries?

Evidence-based dentistry (EBD) is an offspring of Evidence-based health care. It simply involves the conscientious, explicit and judicious use of the current best available 
evidence in conjunction with clinical experience and patient's preference in decision making regarding patient's dental health care. The essential departure from the conventional model for clinical decision making is the need to search for the current best available evidence [4]. Unlike conventional literature review, the techniques of critical appraisal exercise must be learnt, mastered and applied by a practitioner of evidence-based dentistry. Access to webbased computerized medical databases must be guaranteed and there must be personal motivation to pursue the course.

Activities in the field of evidence-based dentistry has increased tremendously in the $21^{\text {st }}$ century, more and more practitioners are joining the train, more education on the subject is being provided to elucidate the knotty areas and there is increasing advocacy for the emergence of the field into a specialty discipline [5]. Indeed, some undergraduate and postgraduate programs in the developed world have either incorporated the subject in their curricula or contemplating to do so [6]. However, it is notable that not much has been heard of the evolutionary trend of Evidence-based dentistry in the developing countries of the world.

In this article, an example is made of the Nigerian state where a pilot investigation into the current level of Evidence-based dental practice was conducted with the following objectives:

i. To assess the awareness and knowledge of the principles of EBD at the dental schools.

ii. To know if there are established evidence-based practice groups at the dental schools/teaching hospitals.

iii. To know what presently forms the basis for decision making in patient care at the dental centers.

iv. To know if the principles of EBD are currently taught in the undergraduate curriculum and /or postgraduate curriculum of the training schools.

v. To find out the main obstacles to Evidence-based dentistry in the country.

Table 1. EBD Articles from Nigeria

\begin{tabular}{|l|c|c|}
\hline Correspondence Author & Title & Citation \\
\hline \hline 1. Adeyemo WL & $\begin{array}{c}\text { Evidence-based dental practice: Part I } \\
\text { Formulating clinical questions and searching } \\
\text { for answers }\end{array}$ & Nig Q J Hosp Med 2007; 17(2): 58-62 \\
\hline 2. Adeyemo WL & $\begin{array}{c}\text { Evidence-based dental practice: Part II } \\
\text { Levels and quality of evidence and research } \\
\text { designs }\end{array}$ & Nig Q J Hosp Med 2007; 17(3): 120-125 \\
\hline 3. Adeyemo WL & $\begin{array}{c}\text { Evidence-based dental practice: Part III } \\
\text { Critical appraisal of the literature, relevance } \\
\text { and application of evidence }\end{array}$ & Nig Q J Hosp Med 2007; 17(3): 165-169 \\
\hline 4. Adeyemo WL & $\begin{array}{c}\text { Is there evidence against evidence-based } \\
\text { dentistry }\end{array}$ & Am J Orthod Dentofacial Orthop. 2007; 132: 3 \\
\hline 5. Akadiri OA & $\begin{array}{c}\text { Assessment of difficulty in third molar } \\
\text { Surgery - A systematic review }\end{array}$ & J Oral Maxillofac Surg 2009; 67: 771-774 \\
\hline 6. Ajayi EO & \begin{tabular}{c} 
Evidence-based paradigm in orthodontics \\
\hline
\end{tabular} & Nig Q J Hosp Med 2007; 17(2): 79-81 \\
\hline
\end{tabular}

\section{THE INVESTIGATION}

In a multi-step approach, the current trend of Evidencebased dental practice in Nigerian dental schools/tertiary dental centers was investigated. First, an electronic search for articles of Nigerian origin discussing the subject of evidencebased dentistry was conducted via google, pubmed and medline search. The keywords employed for the search are 'Evidence-based dentistry', 'Evidence-based dental practice', 'Critical appraisal', 'hierarchy of evidence', 'Systematic review', 'meta-analysis', and 'Nigeria' in different combinations. Finally, we conducted a telephone interview of some faculty members/ dental specialists and residents doctors across the four fully accredited dental schools/teaching hospitals in the country. The discussions were premised around the objectives of the investigation stated above.

\section{FINDINGS}

The electronic search yielded six articles traceable to three correspondence authors (Table 1). The observations from the oral interviews are presented under various subheadings as follows:

\section{Awareness and Knowledge}

All interviewees were aware of the principles of Evidence-based dentistry. However, the level of knowledge varied and was generally below average. Very few were aware of the concepts of "critical appraisal exercise" or "hierarchy of evidence".

\section{Existence of EBD study groups}

There is no existing evidence-based dentistry group in any of the dental schools/teaching hospital. However, one faculty informed of an ongoing effort to initiate such a group at his center.

\section{Basis for Decision Making in Patient Care}

Most respondents posit that clinical experience and expertise remain the main basis for decision making in patient care at their centers. However, it was generally believed that 
evidences derived from literature sometimes influence decisions in some cases, especially with rare disease presentations. They however admitted that such evidences are not necessarily subjected to critical appraisal process.

\section{EBD Principles in Curriculum}

It was generally agreed that the principles of EBD are still not incorporated into either undergraduate or postgraduate programs at any of the centers. The faculties with evidence of interest in EBPr however claim to have been introducing the concepts to their students and residents during their own teaching sessions on an extracurricular basis.

\section{Obstacle to EBPr}

The main obstacles to EBPr as opined by most interviewees are;

i. Lack of interest on the part of most practitioners.

ii. The conventional model for decision making is more convenient and has proven effective in most cases of dental health care. It was thought that the benefit derivable from EB -model for clinical decision making is not worth the trouble.

iii. Paucity of reliable and high level evidence in the world dental literature for most dental health conditions. Most available evidences are derived from a different culture and may require cautious application in our settings.

iv. Infrastructural limitations such as erratic electricity power supplies, limited access to web-based subscription medical databases, insufficient access to computers and internet facilities

v. Lack of mentors who are passionate about the field.

\section{DISCUSSION}

Despite its ancient origin, EBPr remains a relatively young discipline whose impacts are just beginning to be validated [6]. Although the theory and principle of EBPr was first postulated about three centuries ago, its growth appears tied to the wheel of ICT. With the recent information explosion powered by contemporary developments in Information and communication technology, ICT-enhanced computerized medical databases have recently evolved and have now made it easier to distribute and access information [7]. With this development, the clamour for evidence driven practice in every specialty of medicine has been in ascendancy since the turn of the last decade. It is therefore desirable of professionals to propagate the use of best evidence in decision making in their respective specialties.

A cursory look into the world dental literature revealed paucity of information in respect of the trend of EBD in the developing countries of Africa. Our investigation incorporating the dental schools in Nigerian teaching hospitals provides a brief on the state of EBD in the country. Our search produced only six articles in dentistry that discusses evidence-based dentistry or incorporates the principles of EBD such as systematic review or meta-analysis. These articles were attributable to three correspondence authors. This is a reflection of rather low activity in EBD research and publications in the field of dentistry in Nigeria. This observation was confirmed following further effort made in contacting some faculties and resident doctors at the four fully accredited dental schools/teaching hospitals in the country.

Undoubtedly, there is currently a significant level of awareness of the discipline of EBD among dental faculties, and residents in Nigeria. However, this has not translated into knowledge of the principles and processes involved in evidence-based dental practice. There is an obvious need for a coalition for the promotion of evidence-based dental practice across the various dental schools. This can be spearheaded by the few authors who have demonstrated interests in the subject.

Conventional model for treatment decision making still prevails across Nigerian dental schools. The situation in private practices is unlikely to be different since most of the practitioners are trained through the same educational system. The desired paradigm shift is only likely to begin from the dental schools and this, by way of introducing EBD principles into both undergraduate and postgraduate curriculum. At the moment this is yet to happen in any of the dental schools. Although there is an increasing tendency to modify clinical decisions based on some evidences derived from recent literature, this phenomenon cannot be confused with "Evidence-based dentistry". It has been described as a clearly different entity conceptualized as "Dentistry based on evidence" $[5,8,9]$. However, there appears to be a natural progression from "experience-based dentistry" through "dentistry based on evidence" and ultimately approaching to "evidence-based dentistry" in our local settings.

Individual opinions and facts gathered from empirical studies have delineated certain obstacles to evidence-based dental practice [10-12]. Among these are barriers related to the practice environment of the oral health care practitioner [12]. Since studies were carried out in different sociocultural and economic environments, it is not surprising that some obstacles are peculiar to a developing economy. The general lack of interest or motivation on the part of faculties/clinicians is most pronounced. EBD requires the learning of new skills not traditionally taught in dental schools [4]. A great deal of motivation is therefore required by older clinicians who are already comfortable with the conventional model for clinical decision making. Since, successful teaching and entrenchment of evidence-based dentistry requires explicit commitment by faculties [4], in an environment where this is lacking, the future of EBD is jeopardized.

Other obstacles encountered in our settings are infrastructural problems such as erratic electricity power supply, lack of internet-ready computers in the dental school libraries and clinical settings, and low institutional and personal subscription to full text journal articles. Also many respondents lament the poor funding of research and lack of sponsors for capacity building programs for faculties.

The most delightful observation during our survey is the increasing awareness and rising enthusiasm of a few faculties and many residents toward the learning and practice of the principles of EBD. This was most unlikely the case a decade ago. It portends progress in the dissemination of the message of EBD and a bright future for EBD in the $21^{\text {st }}$ century, even in a developing economy. The current concerns should be about overcoming the perceived and real obstacles, 
since EBD can only thrive on the threshold of appropriate infrastructure and well motivated and properly trained professionals.

The importance of evidence in teaching and in support of clinical decisions is well established in health care, including dentistry [13]. It has been said that the future of dentistry depends on the consistent and concerted marriage of the "best available" research evidence with the diagnostic modalities and the treatment interventions our patients need [14]. This makes the campaign for EBD an obligatory responsibility of all dentists who have found it most effective in patient management with a view to stimulating the interest in others. The cross cultural and cross-national differential growth rate of EBD though understandable; it should be unacceptable. Regulated efforts are desirable to create equilibrium such that patients in some parts of the world are not deprived of the best and affordable treatments they deserve. We must crave the intervention of the WHO in providing equitable funding for research across national, socio-cultural and economic divides. The body may need to articulate a position on evidence-based dental practice to which member countries should owe obligations.

This is particularly so in the light of the obstacles to Evidence-based dentistry peculiar to less developed economy. Issues of infrastructural and socioeconomic constraints are capable of shriveling the growth or crippling the progress of global campaign for Evidence-based dentistry in the third world countries. For the teachings of EBD to go beyond mere academic exercise, all stakeholders in every country must commit to their respective roles and play them well. In which case, the government, private proprietors, third party payers, consumers and dentists have roles to play, so that the budding hope for improved health care thriving in the soil of EBD can fully crystallize across the world irrespective of socio-economic strata.

Although, this account is discussed based on our observation in Nigeria, the situation is not likely to be too different from other developing countries; especially in Africa. Evidence-based dentistry is yet to assume the desired momentum in the $21^{\text {st }}$ century in these countries. What gladdens the heart however is that the train of evidence-based dentistry is already permeating the entire world; it appears to travel along the gradient of socioeconomic development, started out from the very advanced countries of Europe and America but surely plying on the rails of Africa and other developing nations at the moment. With the promising future evolving in the developing countries, certainly, evidence-based dentistry is here to stay.

\section{ACKNOWLEDGEMENT}

We acknowledge Mrs. MO Akadiri for the assistance rendered in preparing the manuscript.

\section{REFERENCES}

[1] Grahame-Smith D. Evidence based medicine: socratic dissent. BMJ 1995; 310: 1126-7.

[2] Evidence based medicine; in its place [editorial]. Lancet 1995; 346 785.

[3] Chiappelli F, Prolo P. The meta-construct of evidence-based dentistry. Part 1. Evid Base Dent Pract 2001; 1: 159-65.

[4] Dodson TB. Evidence based medicine: its role in the modern practice and teaching of dentistry. Oral Surg Oral Med Oral Pathol Oral Radiol Endod 1997; 83: 1927.

[5] Chiappelli F, Cajulis OS. Transitioning toward evidence-based research in the health sciences for the XXI century. eCAM 2008; 5(2): 123-8.

[6] Sackett DL, Rosenberg WMC, Gray JAM, Haynes RB, Richardson WS. Evidence based medicine: what it is and what it isn't: It's about integrating individual clinical expertise and the best external evidence BMJ 1996; 312(7023): 71-2.

[7] Greenhalgh T. How to read a paper. the medline database. BMJ 1997; 315: 180-3.

[8] Chiappelli F, Navarro AM, Moradi DR, Manfrini E, Prolo P. Evidence-based research in complementary and alternative medicine III: treatment of patients with alzheimer's disease. Evid Based Complement Alternat Med 2006a; 3: 411-24.

[9] Chiappelli F, Prolo P, Rosenblum M, Edgeron M, Cajulis OS. Evidence-based research in complementary and alternative medicine II: the process of evidence-based research. Evid Based Complement Alternat Med 2006b; 3: 3-12.

[10] Iqbal A, Glenny AM. General dental practitioners' knowledge of and attitudes towards evidence-based practice. Br Dent J 2002; 193: 587-91.

[11] Rabe P, Holmén A, Sjögren P. Attitudes, awareness, and perceptions on evidence-based dentistry and scientific publications among dental professionals in the county of Holland, Sweden: a questionnaire survey. Swed Dent J 2007; 31: 113-20.

[12] Hannes K, Norré D, Goedhuys J, Naert I, Aertgeerts B. Obstacles to implementing evidence-based dentistry: a focus group-based study. J Dent Educ 2008; 72: 736-44.

[13] Healey D, Lyons K. Evidence-based practice in dentistry. New Zealand Dent J 2002; 98: 32-35.

[14] Chiappelli F, Cajulis OS, Newman MG. Comparative effectiveness research in evidence-based dental practice. J Evid Base Dent Pract 2009; 9: 57-58.

(C) Adeniyi and Lanre; Licensee Bentham Open.

This is an open access article licensed under the terms of the Creative Commons Attribution Non-Commercial License (http://creativecommons.org/licenses/by-nc/3.0/) which permits unrestricted, non-commercial use, distribution and reproduction in any medium, provided the work is properly cited. 